\title{
Prevalence of acute conjunctivitis caused by chlamydia, adenovirus, and herpes simplex virus in an ophthalmic casualty department
}

\author{
PETER K. WISHART, ${ }^{1}$ CHARLES JAMES, ${ }^{1}$ MANIJEH S. WISHART, ${ }^{2}$ \\ AND SOHRAB DAROUGAR ${ }^{2}$ \\ From ${ }^{1}$ Moorfields Eye Hospital, High Holborn, London WC1, and the ${ }^{2}$ Subdepartment of Virology, \\ Institute of Ophthalmology, Judd Street, London WC1
}

SUMmARY The causes of acute conjunctivitis in 140 consecutive patients attending an ophthalmic casualty department in London were investigated. Laboratory evidence of infection with Chlamydia trachomatis, adenovirus, or herpes simplex virus was found in $52(37 \%)$ cases. In 70 cases $(50 \%)$ no evidence of infection with these agents was found. In the remaining 18 cases $(13 \%)$ laboratory results were inconclusive. The importance of these findings, the role of laboratory investigations in the differential diagnosis of acute conjunctivitis, and their cost-benefit are discussed.

Acute conjunctivitis (AC) is a common reason for attendance of patients at ophthalmic casualty (outpatient) departments. Most ophthalmologists take little interest in $\mathrm{AC}$ because of difficulties in making aetiological diagnoses and the assumption that $A C$ is a self-limiting and benign disease.

Bacterial AC is usually self-limiting, and antibiotic treatment is generally empirical. ${ }^{1}$ Viral and chlamydial AC in their early stages cannot be differentiated clinically from bacterial or allergic AC. Yet laboratory tests for the diagnosis of these infections are not used routinely. AC caused by herpes simplex virus (HSV) is potentially blinding, and AC due to adenovirus (AV) is responsible for outbreaks of keratoconjunctivitis. ${ }^{2-6}$ Chlamydia trachomatis (CT) conjunctivitis is generally associated with chlamydial genital infections. These genital infections may cause serious complications such as pelvic inflammatory disease, ${ }^{7}$ infertility, ${ }^{7}$ Reiter's disease,${ }^{8}$ ophthalmia neonatorum, ${ }^{9}$ and pneumonia in the newborn ${ }^{10}$ if not detected and treated promptly.

To determine the frequency with which CT, AV, and HSV cause AC, consecutive patients attending an ophthalmic casualty department were investigated for evidence of infection with these agents irrespective of the clinical diagnosis. This study also served to determine whether or not routine virological and chlamydial investigations are necessary in cases of Correspondence to Professor S. Darougar, Institute of Ophthalmology, Judd Street, London WC1H 9QS.
$\mathrm{AC}$, and if the cost of these investigations can be justified.

\section{Patients and methods}

All patients attending the Casualty Department, Moorfields Eye Hospital, High Holborn, London, because of AC during the three months May to July 1982 were included. Patients with symptoms persisting for more than two weeks were excluded except for those with a moderate to severe follicular conjunctivitis. Patients with corneal marginal ulceration and a chronic lid disease and children under 8 years were excluded. Cases were classified as mild, moderate, or severe, and patients were not excluded from this study because of the mildness of their condition.

\section{CLINICAL EXAMINATION}

A clinical history was taken and patients were examined with a slit-lamp. Attention was paid to the signs in the tarsal and bulbar conjunctivae, fornices, and lids. The cornea was examined and stained with fluorescein or rose Bengal to detect any epithelial abnormality.

\section{LABORATORY INVESTIGATIONS}

Tears were collected by placing a cellulose sponge in the lower conjunctival fornix. ${ }^{11}$ Blood was collected by soaking a cellulose sponge with blood following a 
finger stab. ${ }^{11}$ Tear and blood sponges were examined for the presence of type-specific antibodies to CT and HSV by means of microimmunofluorescence (microIF) tests. ${ }^{11} 12$

Conjunctival swabbings were collected from the upper and lower lid conjunctivae by the method described previously. ${ }^{13}$ Swabs were then placed in $2 \mathrm{SP}$ transport medium ${ }^{14}$ containing $3 \%$ inactivated calf serum, stored in a liquid nitrogen refrigerator $\left(-180^{\circ} \mathrm{C}\right)$, and transferred to the laboratory. Specimens were divided into two aliquots, one of which was inoculated on to monolayers of HEp2 cells for virus isolation by a rapid culture test for $\mathrm{AV}^{15}$ and $\mathrm{HSV}^{16}$ which were identified after 48 hours incubation by an immunofluorescent staining technique. The second aliquot was inoculated on to monolayers of McCoy cells treated with cycloheximide for CT isolation. ${ }^{17}$

The patients were initially treated with chloramphenicol drops except for those with herpetic ulceration, who were treated with Oc 2-iodo-5deoxyuridine, five times a day. All patients were asked to attend again one week after their first visit for re-examination and checking of laboratory results. When there was laboratory evidence of CT, AV, or HSV infection, the patients were referred to the External Eye Diseases Clinic of Moorfields, where their further management was undertaken. If there was no evidence of infection with CT, AV, or HSV, and the patient had improved, he was discharged.

\section{Results}

A total of 140 patients with AC were investigated, 82 $(59 \%)$ of whom had moderate to severe conjunctivitis. A definitive or presumptive clinical or laboratory diagnosis of $\mathrm{CT}, \mathrm{AV}$, or HSV infection was made in $52(37 \%)$ patients. In $18(13 \%)$ patients low levels of antibodies against CT or HSV were found, which suggested previous infection. In 70 $(50 \%)$ patients negative isolation tests and the absence of specific antibodies showed that these agents were not the cause of AC.

CT infection was confirmed or supported by laboratory tests in $12(9 \%)$ patients. Seven of these were positive for $\mathrm{CT}$ in cell culture. In nine patients type-specific antichlamydial IgG in serum against serotypes $D$ to $K$ at a level of $1 / 64$ or higher, suggestive of an active chlamydial infection, ${ }^{11}$ was detected, while only four of these were positive in cell culture. In tears of nine patients type-specific IgG and/or IgA antibodies against serotypes $D$ to $K$ at a level of $1 / 8$ or higher, suggestive of an active chlamydial ocular infection, ${ }^{11}$ were detected. In patients with positive tears all had antibodies in sera, but CT was isolated from only six patients.
$\mathrm{AV}$ was isolated from conjunctival swabbings from $11(8 \%)$ patients. No serological tests for AV infection were carried out.

A definitive or presumptive clinical or laboratory diagnosis of HSV ocular infection was made in 29 ( $21 \%$ ) patients. HSV was isolated from conjunctival swabbings of eight $(6 \%)$ patients. Of nine patients with clinical evidence of HSV infection four were isolation-positive. In addition, HSV was isolated from four patients without typical signs of HSV infection (lid and/or corneal lesions). In a further 16 patients type-specific IgG antibodies in sera at a level of $1 / 128$ or higher, or in tears at a level of $1 / 8$ or higher, suggestive of active HSV infection, ${ }^{12}$ were found. These patients had no clinical or laboratory evidence of CT or AV infection or allergy.

A good correlation between the clinical diagnosis and laboratory findings was found in 19 out of 122 $(16 \%)$ patients in whom CT, AV, or HSV infection was confirmed or excluded.

\section{Discussion}

In a group of 140 patients with $\mathrm{AC}$ a definitive or presumptive diagnosis of $\mathrm{CT}, \mathrm{AV}$, or $\mathrm{HSV}$ infection was made in $52(37 \%)$.

CT conjunctivitis was diagnosed in $12(9 \%)$ patients during the three-month period, of whom seven were isolation-positive. In Bristol only 13 cases of isolationpositive CT ocular infection were found in 30000 new patients attending ophthalmic outpatient clinics during a period of two years. ${ }^{18}$ The very low rate of CT ocular infection reported in Bristol may be due to the fact that isolation tests were carried out only in patients who were clinically suggestive of CT ocular infection, whereas in our study in London tests were carried out in all cases of $\mathrm{AC}$.

$\mathrm{AV}$ was isolated from $11(8 \%)$ cases. The number of proved cases of $\mathrm{AV}$ infection in our series might have been higher if we had also carried out serological tests. AV is a major cause of ocular morbidity in London. In previous studies we isolated serotypes 3, 7 , and $\mathbf{1 0}$ from more than half of the cases and serotypes $3,4,7,8,10$, and 19 from outbreaks in the hospital and in the community. ${ }^{19}$ The clinical features of AV infection in London varied considerably. It was found that, while most serotypes can cause epithelial punctate keratitis, the most severe and prolonged conjunctivitis and subepithelial punctate keratitis was caused by serotypes $3,4,5,7,8,10$, and $19 .{ }^{20}$

A definitive or presumptive diagnosis of HSV ocular infection was made in $29(21 \%)$ patients. This is comparable to the rate reported by Jones. ${ }^{21}$ Of the eight patients who were HSV positive four were suffering from AC without typical clinical signs of 
HSV eye infection (lid lesions and/or corneal ulcers). This finding confirms a previous report that HSV can cause $\mathrm{AC}{ }^{22}$ In this study serological evidence of active HSV infection (HSV-IgG antibodies at level of $1 / 128$ or higher in blood or at a level of $1 / 8$ or higher in tears) was found in 16 patients. HSV was not isolated from these patients, and we were unable to find clinical or laboratory evidence of bacterial, CT, or AV infection or allergy. Studies in our laboratory have shown that in HSV infection the presence of type-specific HSV-IgG antibodies equal to or higher than the above mentioned levels in the blood and in tears is suggestive of active HSV infection ${ }^{12}$ (unpublished data). These observations are similar to those made in chlamydial ocular infection, where the presence of type-specific antibodies at or above certain levels in the blood and tears is considered suggestive of active $\mathrm{CT}$ ocular infection. ${ }^{11}$

$\mathrm{AC}$ is a common cause for the attendance of patients at ophthalmic outpatient clinics. If it is not diagnosed and managed correctly, it may cause patients to pay several visits to the clinic or attend other hospitals and clinics in search of an accurate diagnosis and management. Tullo et al. ${ }^{18}$ showed that $30 \%$ of their patients who were suffering from chlamydial conjunctivitis had been under the care of the hospital for an average of nine weeks before the diagnosis was made. In the present study a correct clinical diagnosis was achieved in only $16 \%$ of the patients. We consider it surprising that the diagnosis and management of $\mathrm{AC}$ is generally left to rather inexperienced junior staff in outpatients clinics, without provision of adequate laboratory services.

In this study two ophthalmic registrars were able to provide correct management for 52 patients because of the provision of diagnostic laboratory tests. In addition they were able to discharge 70 patients, in whom CT, AV, or HSV were excluded as possible causes of infection. Without laboratory support each of these 122 patients might have been expected to make, on average, a further three outpatient visits before a definitive or presumptive diagnosis could be made. The savings due to the reduction in the number of unnecessary visits amounted to $£ 25620$ (the direct and indirect costs of a visit to an outpatient clinic under the National Health service is estimated at f70), whereas the direct and indirect costs of the laboratory services provided for this study were estimated to be $£ 3500$ ( $£ 25$ per patient). The laboratory services are therefore highly cost effective.

The cause of $\mathrm{AC}$ in $88(63 \%)$ cases remained obscure. It is probable that other viruses, bacteria, and allergy may be responsible for at least some of these cases. The high number of undiagnosed cases of AC indicates that there is an urgent need for the development of simple, rapid, and more sensitive tests for the diagnosis of viral and bacterial infections and allergy.

The authors are grateful to Dr P. Walpita, Mr T. Forsey, and Mr P. Yearsley for the laboratory support and to the sister and nursing staff of the Casualty Department, Moorfields Eye Hospital, High Holborn, for their help with collection of clinical specimens. This project was supported by the Department of Health and Social Security through Moorfields Eye Hospital.

\section{References}

1 Wilson L. Bacterial conjunctivitis. In: Duane TD, ed. Clinical Ophthalmology. Hagerstown: Harper and Rowe, 1980: 4: 9.

2 Jones BR. Adenovirus infection of the eye in London. Trans Ophthalmol Soc UK 1962; 82: 621-40.

3 Jawetz E. The story of shipyard eye. Br Med J 1959; i: 873-6.

4 Dawson CR, Darrell R, Hanna L, Jawetz E. Infection due to adenovirus type 8 in the USA: community wide infection with adenovirus type 8. N Engl J Med 1963; 268: 1034-7.

5 Dawson CR, Darrell R. Infections due to adenovirus type 8 in USA. An outbreak of EKC originating in a physician's office. $N$ Engl J Med 1963; 268: 1031-3.

6 Laibson PR, Ortolan G, Dupre-Strachan S. Community and hospital outbreak of epidemic keratoconjunctivitis. Arch Ophthalmol 1968; 80: 467-73.

7 Weström L, Mårdh PA. Chlamydial salpingitis. Br Med Bull 1983; 39: 145-50.

8 Keat AC. Reiter's syndrome. Br Med J 1978; i: 605-7.

9 Freedman A, Al-Hussaini MK, Dunlop EMC, et al. Infection by TRIC agent and other members of the Bedsonia group; with a note on Reiter's disease-II. Ophthalmia neonatorum due to TRIC agent. Trans Ophthalmol Soc UK 1966; 86: 313-20.

10 Beem MO, Saxon EM. Respiratory tract colonization and a distinctive pneumonia syndrome in infants infected with Chlamydia trachomatis. N Engl J Med 1977; 293: 306-10.

11 Darougar S, Treharne JD, Minassian D, El-Sheikh H, Dines RJ, Jones BR. Rapid serological test for diagnosis of chlamydial ocular infections. BrJ Ophthalmol 1978; 62: 503-8.

12 Forsey T, Darougar S. Indirect MIF test for detecting typespecific antibodies to herpes simplex virus. J Clin Pathol 1980; 33: 171-6.

13 Darougar S, Jones BR. Conjunctival swabbing for isolation of TRIC agent. BrJ Ophthalmol 1971; 55: 585-90.

14 Gordon FB, Harper IA, Quan AL, Treharne JD, Dwyer RStC, Garland JA. Detections of chlamydia (bedsonia) in certain infections of man. I. Laboratory procedures: comparison of yolk sac and cell culture detection for detection and isolation. $J$ Infect Dis 1969; 120: 451-62.

15 Darougar S, Walpita P, Thaker U, Viswalingam N, Wishart MS. Rapid culture test for adenovirus isolation. $\mathrm{Br} \mathrm{J}$ Ophthalmol in press.

16 Darougar S, Gibson JA, Thaker U. Effect of centrifugation on herpes simplex virus isolation. J Med Virol 1981; 8: 231-5.

17 Ripa KT, Mårdh P-A. New simplified culture techniques for Chlamydia trachomatis In: Hobson D, Holmes KK, eds. Nongonococcal urethritis and related infections. Washington, DC: American Society for Microbiology, 1977: 323-7.

18 Tullo AB, Richmond SG, Easty DL. Presentation and incidence of paratrachoma in adults. J Hyg (Camb) 1981; 87: 63-9.

19 Darougar S, Walpita P, Thaker U, Viswalingam N, Gardner L, McSwiggan DA. Adenovirus serotypes isolated from ocular infections in London. Br J Ophthalmol 1983; 67: 111-4.

20 Darougar S, Grey RHB, Thaker U, McSwiggan DA. Clinical and epidemiological features of adenovirus keratoconjunctivitis in London. Br J Ophthalmol 1983; 67: 1-7.

21 Jones BR. Management of ocular herpes. Trans Ophthalmol Soc UK 1959; 79: 425-37.

22 Darougar S, Hunter PA, Viswalingam N, Gibson JA, Jones BR. Acute follicular conjunctivitis due to $\mathrm{HSV}$ in London. $\mathrm{Br} J$ Ophthalmol 1978; 62: 843-9. 